\title{
PENDETEKSI KETINGGIAN LEVEL AIR DENGAN TAMPILAN LCD BERBASIS MIKROKONTROLLER ATMEGA 8 SERTA LED BUZZER DAN SEVEN SEGMENT SEBAGAI PERINGATAN DINI KENAIKAN AIR PASANG (ROB) BERBASIS PROGRAMMABLE LOGIC CONTROLLER CP1E-E40DR-A
}

\author{
Rizal Fauzan Adi Rahardjo, Heru Winarno \\ Program Studi Diploma III Teknik Elektro \\ Fakultas Teknik Universitas Diponegoro
}

\begin{abstract}
Rizal Fauzan Adi Rahardjo, Heru Winarno, in paper water level detection based atmega 8 microcontroller with lcd display, led, buzzer and seven segment as early warning of post water (rob) increase based CP1E-E40DR-A programmable logic controller explain that as a result of the overflow of the tidal sea water in rural areas sriwulan sayung District of Demak, the tidal water easily entered into the residential area, which can be fatal if not in further tackle. Tidal flood has become commonplace in the area Sriwulan Sayung District of Demak. However, the longer the tidal flood is troubling and very disturbing society. So I took the initiative to create a miniature tidal flood prevention. Height of the water level of a river that flows directly into the sea will be detected by the sensor. The sensors will send data to the PLC and will be displayed by the seven segment. Further increase in the water level of the river will also affect the water level in the ditch homes residents. Height of the ditch water level is detected by the sensor which will send data to the PLC and then displayed by seven segment LCD and previously through the microcontroller atmega 8 . The maximum height of the water level gutter will be marked with berbunyinya buzzer and LED life.
\end{abstract}

Keywords : Sensor, Seven Segment, Microcontroller Atmega 8 , LCD , LED, buzzer.

\section{PENDAHULUAN \\ Latar Belakang}

Seiring terjadinya banjir rob akibat meluapnya air laut di daerah desa Sriwulan Kecamatan Sayung Kabupaten Demak, maka dengan mudah air rob masuk ke pemukiman warga, yang dapat berakibat fatal jika tidak di tanggulangi lebih lanjut. Penanggulangan rob yang telah dilakukan oleh warga adalah membuat bendungan sepanjang sungai dan membuang air rob yang telah masuk ke pemukiman warga ke sungai secara manual menggunakan pompa penyedot air. Meluapnya air rob yang sering terjadi di desa Sriwulan membuat warga gerah dan merasa capek karena harus sering-sering memompa air rob tersebut di buang ke sungai secara manual.

\section{LANDASAN TEORI}

Catu Daya

Catu Daya atau power supply adalah suatu rangkaian yang berfungsi sebagai sumber daya untuk mengoperasikan rangkaian yang lain. Jenis rangkaian catu daya cukup banyak tetapi untuk rangkaian yang sederhana biasanya terdiri dari transformator, penyearah, filter, dan regulator. Tegangan AC yang berasal dari jala-jala PLN akan diturunkan tegangannya dengan transformator penurun tegangan sesuai dengan tegangan yang dikehendaki. Tegangan yang telah diturunkan oleh transformator tersebut disearahkan oleh penyearah dioda sehingga tegangan keluaran berupa tegangan DC namum masih mengandung ripple, tegangan ripple tersebut dapat dihilangkan dengan memasang kapasitor sebagai filter. Agar tegangan keluaran catu daya stabil maka diperlukan rangkaian peregulasi tegangan.

\section{Transformator}

Transformator adalah alat yang dapat memindahkan dan mengubah energi listrik dengan frekuensi tertentu dari suatu rangkaian ke rangkaian yang lain melalui suatu gandengan magnet dan berdasarkan prinsip induksi magnet tanpa mengubah frekuensinya.

Transformator mempunyai dua buah lilitan, yaitu lilitan primer dan lilitan sekunder yang dililitkan pada suatu inti dan saling terisolasi antara yang satu dengan yang lain. Perbandingan besar tegangan yang muncul pada lilitan sekunder dan lilitan primer ditentukan oleh jumlah lilitan yang terdapat pada bagian sekunder maupun primer.

Penyearah

Catu daya yang kami buat menggunakan penyearah gelombang penuh dengan 4 buah dioda (dioda bridge atau sistem jembatan). Rangkaian penyearah sistem jembatan ini adalah rangkaian penyearah gelombang penuh tetapi tidak mengggunakan center tap pada trafonya (seperti pada penyearah gelombang penuh yang menggunakan 2 buah dioda). Penggunaan penyearah gelombang penuh dimaksudkan agar dapat mengalirkan arus dalam satu gelombang penuh sehingga tegangan keluaran lebih mudah diratakan dan dapat menghasilkan nilai konstan. Seperti yang terlihat pada Gambar 1. 


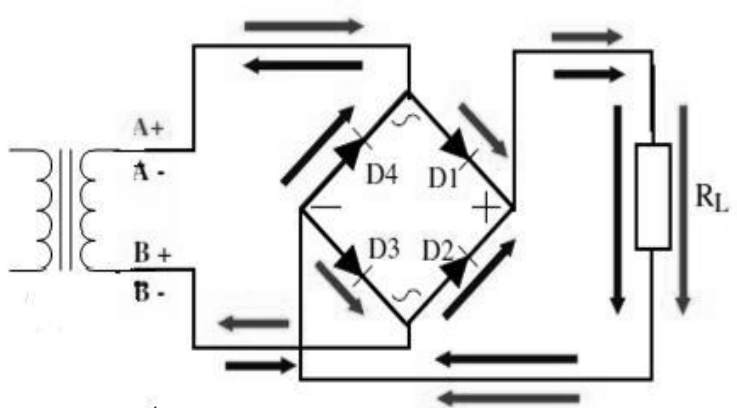

Gambar 1. Rangkaian Penyearah Gelombang Penuh Sistem Jembatan

Filter

Filter merupakan salah satu cara pemerataan penyearah gelombang penuh. Tegangan searah yang dihasilkan oleh penyearah setengah gelombang maupun gelombang penuh (penyearah jembatan) memiliki riak yang cukup besar (gelombang tegangan tidak rata). Tegangan searah seperti ini tidak memenuhi syarat untuk diberikan kepada komponen-komponen elektronika yang terdapat dalam radio, televisi, dan perangkat lainnya , yang membutuhkan tegangan searah lebih rata. Secara sederhana tegangan searah dapat diratakan dengan memasang sebuah kapasitor elektrolit seperti pada Gambar 2.

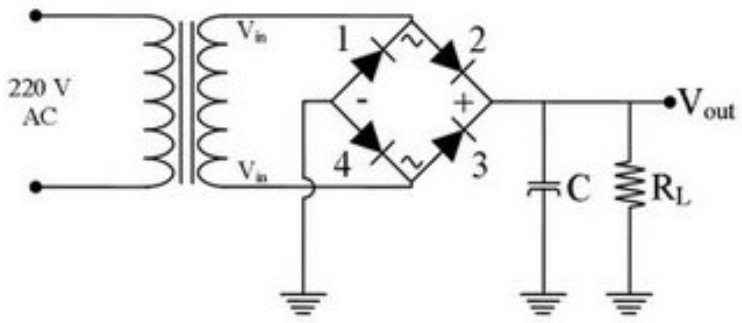

Gambar 2. Rangkaian Penyearah Gelombang Penuh Berfilter

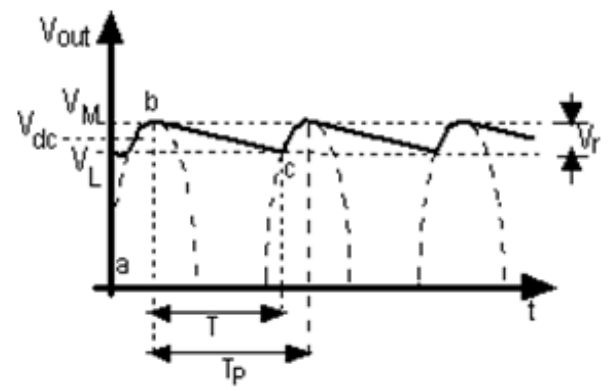

Gambar 3. Bentuk Sinyal Berfilter

$$
\mathrm{Vr}=0.5 \times \mathrm{I} \times \mathrm{T} / \mathrm{C}
$$

Dimana :

Vr : Tegangan ripple dalam volt

I : Arus dalam ampere

$\mathrm{T}$ : Periode dalam detik, dengan f PLN $50 \mathrm{~Hz}$, maka $\mathrm{T}=20 \mathrm{mS} / 0.02 \mathrm{~S}$

C : Nilai kapasitor penyearah dalam farad
Regulator

Regulator di sini berupa IC 7805T dan IC 7812 yang sebagai peregulasi tegangan. Rangkaian terpadu ( Integrated Circuit ) jenis 78XX adalah rangkaian terpadu regulator yang menghasilkan tegangan konstan sebesar XX Volt. Selain menggunakan IC, regulator terdiri dari dioda zener. Fungsi dari dioda zener adalah untuk mempertahankan tegangan output tetap konstan. Dioda zener sering disebut voltage-regulator diode (dioda pengatur tegangan) karena mempertahankan tegangan output tetap konstan meskipun arus yang melaluinya berubah.

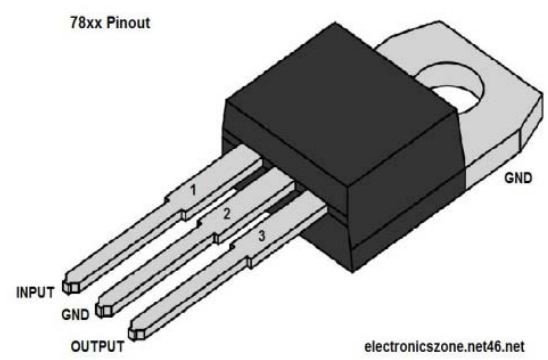

Gambar 4. IC 78XX

\section{PLC ( Programmable Logic Controller )}

PLC ( Programmable Logic Controller ) dapat dibayangkan seperti sebuah personal computer konvensional ( konfigurasi internal pada PLC mirip sekali dengan konfigurasi computer internal pada personal computer). Di dalam otak ( CPU = Control Processing Unit ) PLC dapat dibayangkan seperti kumpulan ribuan relay. Akan tetapi bukan berarti didalamnya terdapat banyak relay dalam ukuran yang sangat kecil.

\section{Prinsip Kerja PLC}

Data-data berupa sinyal dari peralatan input luar (external input device) diterima oleh sebuah PLC dari sistem yang dikontrol. Peralatan input luar tersebut antara lain berupa saklar, tombol, sensor, dan lain-lain. Data-data masukan yang masih berupa sinyal analog akan diubah oleh modul input A/D (analog to digital input module) menjadi sinyal digital. Selanjutnya oleh unit processor sentral atau CPU yang ada di dalam PLC sinyal digital dan disimpan di dalam ingatan (memory). Keputusan diambil CPU dan perintah yang diperoleh diberikan melalui modul output D/A ( digital to analog output module).

\section{CP1E-E40DR-A}

Dalam penelitian ini jenis PLC yang digunakan adalah CP1E-E40DR-A. Unit CPU dari CP1E terbagi menjadi empat jenis sesuai dengan terminal input-outputnya, yaitu :

- CP1E 10 I/O (terdiri dari 6 input dan 4 output)

- CP1E 14 I/O (terdiri dari 8 input dan 6 output) 
- CP1E 20 I/O (terdiri dari 12 input dan 8 output)

- CP1E 30 I/O (terdiri dari 18 input dan 12 output)

- CP1E 40 I/O (terdiri dari 24 input dan 16 output)

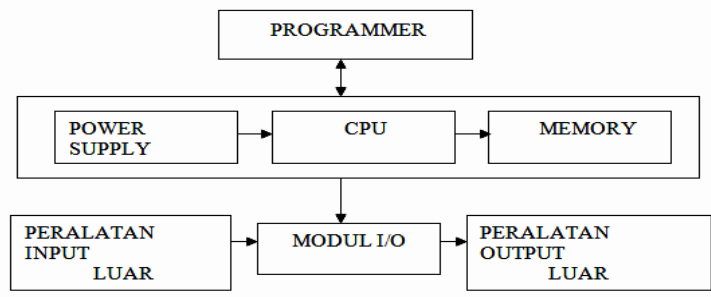

Gambar 5. Blok Diagram Prinsip Kerja PLC

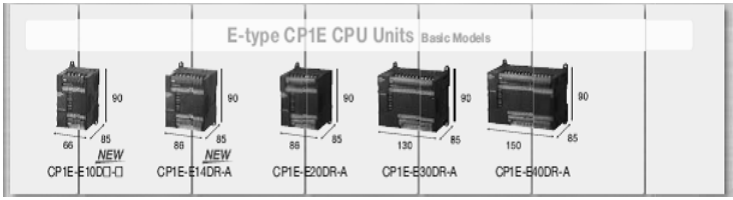

Gambar 6. Jenis-jenis CPU CP1E

Tegangan masukan CP1E adalah 100-240 V AC, 50-60 Hz untuk tipe AC sedangkan untuk tipe DC menggunakan tegangan masukan $24 \mathrm{~V}$ DC. CP1E dapat diprogram melalui Programming Console maupun Sysmac Support System (SSS). Dari keempat jenis unit CPU CP1E di atas yang dipakai dalam pembuatan Tugas Akhir (TA) ini adalah jenis CP1E-E40DR-A dengan 40I/O.

\section{Progammer}

CX progammer adalah sebuah software yang digunakan untuk memprogram PLC sesuai dengan yang diinginkan. Data input PLC ditransfer melalui komputer/laptop dengan menggunakan kabel data USB.

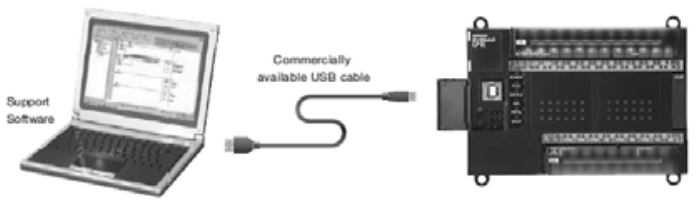

Gambar 7. Transfer Program Dari Laptop Ke PLC Melalui USB Connector

\section{Seven Segment Display}

Display 7 segment merupakan komponen yang berfungsi sebagai penampil karakter angka dan karakter huruf. Display 7 segment sering juga disebut sebagai penampil 7 ruas. Pada display 7 segment juga dilengkapi karakter titik (dot) yang sering dibutuhkan untuk karakter koma atau titik pada saat menampilkan suatu bilangan. Display 7 segment terdiri dari 7 penampil karakter yang disusun dalam sebuah kemasan sehingga dapat menampilkan karakter angka dan karakter huruf.
Terdapat 7 buah penampil dasar dari LED (Light Emiting Diode) yang dinamakan karakter A-F dan karakter dot. Bentuk susunan karakter penampil karakter A-F pada display 7 segment dapat dilihat pada Gambar 8.

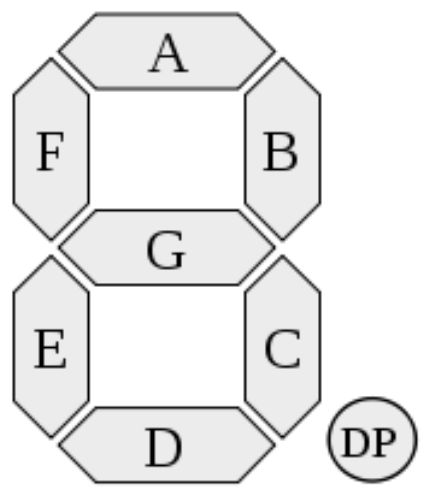

Gambar 8. Bentuk Susunan Karakter Display 7 Segment

Pada dasarnya penampil 7segment merupakan rangkaian 7 buah dioda LED (Light Emiting Diode). Terdapat 2 (dua) jenis rangkaian dasar dari display 7 segment yang dikenal sebagai display 7 segment common anoda (CA) dan common cathoda (CC)

\section{Seven Segment Common Anode (CA)}

Pada display common anoda, untuk mengaktifkan karakter display 7 segment diperlukan logika low (0) pada jalur A-F dan DP. Di bawah ini adalah rangkaian internal display 7 segment common anoda.

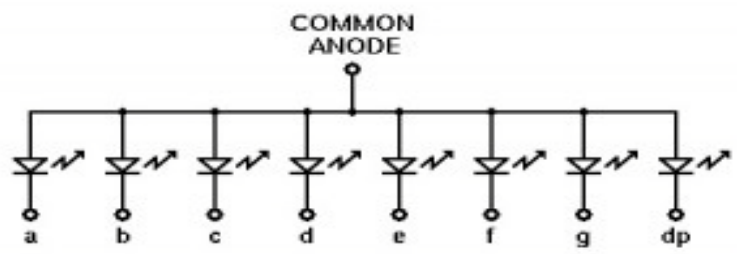

Gambar 9. Rangkaian Internal Display 7 Segment Common Anoda

\section{Seven Segment Common Chatode (CC)}

Berkebalikan dengan seven segment common anode, pada display common chatode, untuk mengaktifkan karakter display 7 segment diperlukan logika high (1) pada jalur A-F dan DP. Di bawah ini adalah rangkaian internal display 7 segment common chatode.

Pada 7 segmen komon katoda, kutub negatif/ground dari LED dihubungkan menjadi satu, sehingga untuk menghidupkan salah satu LED dari Segmen maka pin Led segmen yg bersangkutan 
harus diberikan tegangan "1" atau tegangan bias maju. Sedangkan untuk komon anoda yang menjadi kutub "common" atau "umum” adalah kutub positif dari masing-masing LED. Untuk menghidupkan LED dari segmen dibutuhkan hubungan ke VCC atau kutub positif pada kutub komon dan pin dari Led segmen diberikan tegangan " 0 " atau ground . Tegangan maju dari led 7-segmen beragam sesuai besar kecil display.

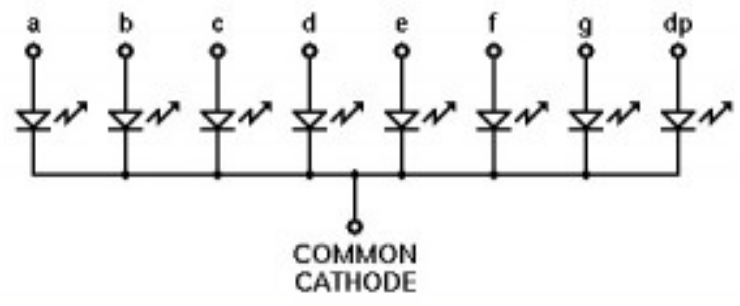

Gambar 10. Rangkaian Internal Display 7 Segment Common Cathoda

\section{LED (Light Emitting Diode)}

LED atau singkatan dari Light Emitting Diode adalah salah satu komponen elektronik yang tidak asing lagi di kehidupan manusia saat ini. LED saat ini sudah banyak dipakai, seperti untuk penggunaan lampu permainan anak-anak, untuk rambu-rambu lalu lintas, lampu indikator peralatan elektronik hingga ke industri, untuk lampu emergency, untuk televisi, komputer, pengeras suara (speaker), hard disk eksternal, proyektor, LCD, dan berbagai perangkat elektronik lainnya sebagai indikator bahwa sistem sedang berada dalam proses kerja, dan biasanya berwarna merah atau kuning. LED ini banyak digunakan karena komsumsi daya yang dibutuhkan tidak terlalu besar dan beragam warna yang ada dapat memperjelas bentuk atau huruf yang akan ditampilkan.

\section{Cara Kerja LED}

Karena LED adalah salah satu jenis dioda maka LED memiliki 2 kutub yaitu anoda dan katoda. Dalam hal ini LED akan menyala bila ada arus listrik mengalir dari anoda menuju katoda. Pemasangan kutub LED tidak boleh terebalik karena apabila terbalik kutubnya maka LED tersebut tidak akan menyala. Led memiliki karakteristik berbedabeda menurut warna yang dihasilkan. Semakin tinggi arus yang mengalir pada led maka semakin terang pula cahaya yang dihasilkan, namun perlu diperhatikan bahwa besarnya arus yang diperbolehkan 10mA-20mA dan pada tegangan 1,6V - 3,5 V menurut karakter warna yang dihasilkan.

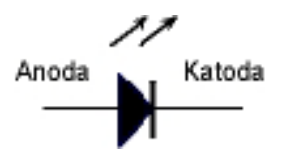

Gambar 11. Simbol LED
LCD

LCD adalah sebuah komponen yang berfungsi untuk menampilkan berbagai macam perintah yang diinputkan melalui sebuah microcontroller. Tampilan pada screen dapat kita lihat/monitor, apakah data yang ditampilkan sesuai dengan yang kita inginkan atau tidak.

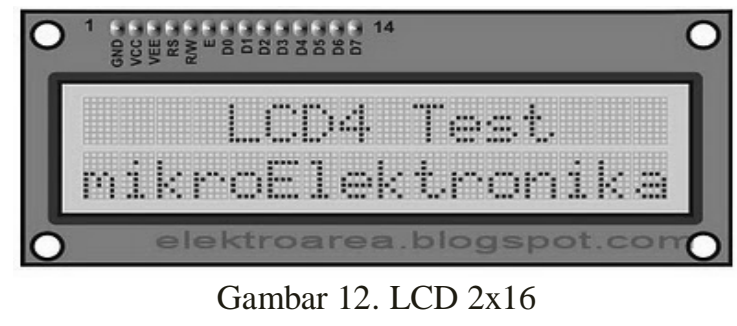

Gambar 12 merupakan gambar LCD 2x16. Pada LCD terdapat 16 pin dan penjelasannya adalah sebagai berikut:

- $\quad$ Pin Gnd/Vdd, Vcc, Vee

Vdd dan Vcc merupakan power supply untuk LCD. Vdd dihubungkan ke ground, Vcc dihubungkan ke power supply DC 5V. Sedangkan Vee digunakan untuk mengatur kontras LCD.

- $\quad$ Pin RS (Register Select)

Pin RS ini berfungsi ntuk mengontrol instruksi LCD. Jika pin RS ini dibuat low (0), maka instruksi yang dijalankan adalah special instruksi LCD. Seperti instruksi untuk On/Of LCD, instruksi untuk geser kursor dan lain sebagainya. Jika pin RS dibuat high (1), maka instruksi yang dijalankan adalah instruksi untuk mengirim informasi/data ke LCD.

- $\quad$ Pin R/W (Read/Write)

Pin RW ini berfungsi untuk membaca informasi dari LCD atau menulis informasi ke LCD. Jika pin R /W ini dibuat low (0), maka informasi yang ada pada data bus $\quad$ (D0 D7 jika mode pemrogramannya 8 bit, D4 D7 jika mode pemrogramannya 4 bit) ditulis ke LCD. Jika pin R/W dibuat high (1), maka informasi pada LCD dibaca oleh program. Informasi yang dibaca hanya satu informasi saja, yaitu membaca status LCD saja. Status LCD dibaca melalui pin D7. Pin R/W selalu di set low (0), kecuali pada saat membaca status LCD di set high (1).

- $\quad$ Pin D0 D7 (Bus data)

Pin-pin ini merupakan 8 bus data yang berfungsi untuk membaca/mengirim informasi dari dan ke LCD. Kedelapan bus data tersebut bisa digunakan dalam 2 kondisi, yaitu :

o Jika mode pemrograman yang digunakan mode 8 bit, maka 8 bus data tersebut digunakan semuanya.

o Jika mode pemrograman yang digunakan 4 bit, maka hanya 4 bus data saja yang 
digunakan, yaitu D4 D7, sedangkan D0 D3 dihubungkan ke ground.

\section{- $\quad$ Pin EN/E (Enable)}

Pin ini merupakan sinyal enable untuk proses pengiriman data ke LCD. Pada saat pengiriman data ke LCD, pin ini di set low (0).

\section{Buzzer}

Buzzer adalah sebuah komponen elektronika yang berfungsi untuk mengubah getaran listrik menjadi getaran suara. Pada dasarnya prinsip kerja buzzer hampir sama dengan loud speaker, jadi buzzer juga terdiri dari kumparan yang terpasang pada diafragma dan kemudian kumparan tersebut dialiri arus sehingga menjadi elektromagnet, kumparan tadi akan tertarik ke dalam atau keluar, tergantung dari arah arus dan polaritas magnetnya, karena kumparan dipasang pada diafragma maka setiap gerakan kumparan akan menggerakkan diafragma secara bolak-balik sehingga membuat udara bergetar yang akan menghasilkan suara. Buzzer biasa digunakan sebagai indikator bahwa proses telah selesai atau terjadi suatu kesalahan pada sebuah alat (alarm).

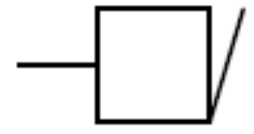

Gambar 13. Simbol Buzzer

\section{Sensor}

Sensor adalah suatu peralatan yang berfungsi untuk mendeteksi gejala-gejala atau sinyal-sinyal yang berasal dari perubahan suatu energi seperti energi listrik, energi fisika, energi kimia, energi biologi, energi mekanik.

Sensor adalah jenis tranduser yang digunakan untuk mengubah besaran mekanis, magnetis, panas, sinar, dan kimia menjadi tegangan dan arus listrik. Sensor sering digunakan untuk pendeteksian pada saat melakukan pengukuran atau pengendalian.

Sensor level air disini menggunakan komparator tegangan. Rangkaian komparator berfungsi untuk membandingkan tegangan input dengan tegangan referensi. Jika pada rangkaian komparator ini menggunakan konfigurasi komparator non infertik yaitu jika tegangan inputnya lebih dari tegangan referensi maka output tegangan komparator akan mendekati VCC atau logic high, jika input tegangan kurang dari tegangan referensi, maka output komparator akan mendekati ground atau logic low.

\section{Mikrokontroller}

Mikrokontroller sebagai sebuah "one chip solution" pada dasarnya adalah rangkaian terintregrasi (Integrated Circuit-IC) yang telah mengandung secara lengkap berbagai komponen pembentuk sebuah komputer. Berbeda dengan penggunaan mikroprosesor yang masih memerlukan komponen luar tambahan seperti RAM, ROM,
Timer, dan sebagainya untuk sistem mikrokontroler, tambahan komponen diatas secara praktis hampir tidak dibutuhkan lagi.

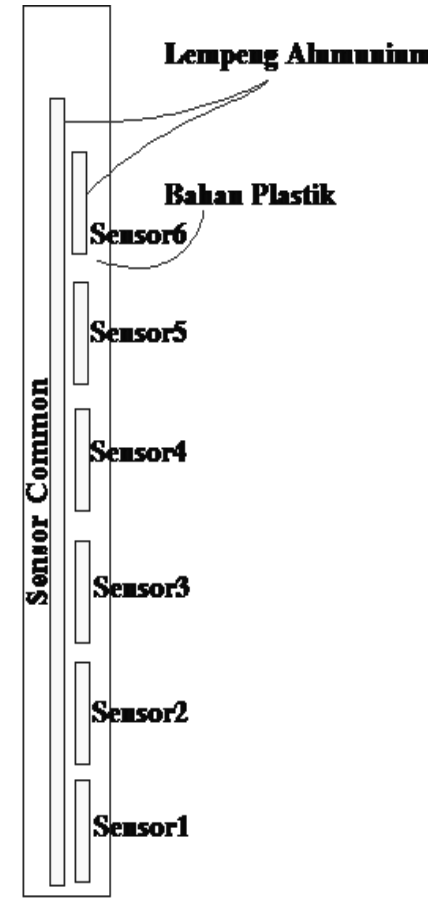

Gambar 14. Bagan Sensor

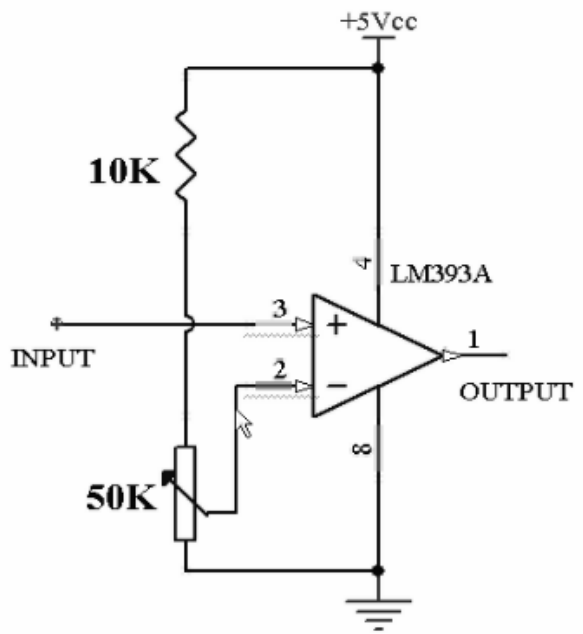

Gambar 15. Skema Komparator Tegangan

\section{Mikrokontroler AVR Atmega8}

AVR merupakan salah satu jenis mikrokontroler yang di dalamnya terdapat berbagai macam fungsi. Perbedaannya pada mikro yang pada umumnya digunakan seperti MCS51 adalah pada AVR tidak perlu menggunakan oscillator eksternal karena di dalamnya sudah terdapat internal oscillator. Jika dibandingkan dengan ATmega8L perbedaannya hanya terletak pada besarnya tegangan yang diperlukan untuk bekerja. Untuk ATmega8 tipe L, mikrokontroler ini dapat bekerja dengan tegangan 
antara 2,7 - 5,5 V sedangkan untuk ATmega8 hanya dapat bekerja pada tegangan antara 4,5-5,5 V.

\section{Konfigurasi Pin Atmega8}

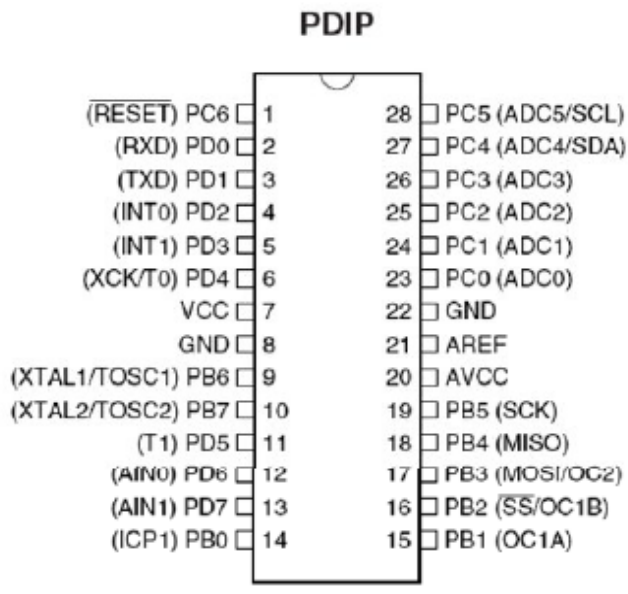

Gambar 16. Konfigurasi Pin Atmega8

ATmega8 memiliki 28 Pin, yang masingmasing pin nya memiliki fungsi yang berbeda-beda baik sebagai port maupun fungsi yang lainnya. Berikut akan dijelaskan fungsi dari masing-masing kaki ATmega8.

- VCC

Merupakan supply tegangan digital.

- GND

Merupakan ground untuk semua komponen yang membutuhkan grounding.

- $\quad$ Port B (PB7...PB0)

Didalam Port B terdapat XTAL1, XTAL2, TOSC1, TOSC2. Jumlah Port B adalah 8 buah pin, mulai dari pin B.0 sampai dengan B.7. Tiap pin dapat digunakan sebagai input maupun output. Port B merupakan sebuah 8-bit bi-directional I/O dengan internal pull-up resistor. Sebagai input, pin-pin yang terdapat pada port B yang secara eksternal diturunkan, maka akan mengeluarkan arus jika pull-up resistor diaktifkan. Khusus PB6 dapat digunakan sebagai input Kristal (inverting oscillator amplifier) dan input ke rangkaian clock internal, bergantung pada pengaturan Fuse bit yang digunakan untuk memilih sumber clock. Sedangkan untuk PB7 dapat digunakan sebagai output Kristal (output oscillator amplifier) bergantung pada pengaturan Fuse bit yang digunakan untuk memilih sumber clock. Jika sumber clock yang dipilih dari oscillator internal, PB7 dan PB6 dapat digunakan sebagai $\mathrm{I} / \mathrm{O}$ atau jika menggunakan Asyncronous Timer/Counter2 maka PB6 dan PB7 (TOSC2 dan TOSC1) digunakan untuk saluran input timer.

- Port C (PC5...PC0)

Port C merupakan sebuah 7-bit bi-directional I/O port yang di dalam masingmasing pin terdapat pull-up resistor. Jumlah pin nya hanya 7 buah mulai dari pin C.0 sampai dengan pin C.6. Sebagai keluaran/output port C memiliki karakteristik yang sama dalam hal menyerap arus (sink) ataupun mengeluarkan arus (source).

- RESET/PC6

Jika RSTDISBL Fuse diprogram, maka PC6 akan berfungsi sebagai pin I/O. Pin ini memiliki karakteristik yang berbeda dengan pin-pin yang terdapat pada port C lainnya. Namun jika RSTDISBL Fuse tidak diprogram, maka pin ini akan berfungsi sebagai input reset. Dan jika level tegangan yang masuk ke pin ini rendah dan pulsa yang ada lebih pendek dari pulsa minimum, maka akan menghasilkan suatu kondisi reset meskipun clock-nya tidak bekerja.

- $\quad$ Port D (PD7...PD0)

Port D merupakan 8-bit bi-directional I/O dengan internal pull-up resistor. Fungsi dari port ini sama dengan port-port yang lain. Hanya saja pada port ini tidak terdapat kegunaan-kegunaan yang lain. Pada port ini hanya berfungsi sebagai masukan dan keluaran saja atau biasa disebut dengan I/O.

- AVCC

Pin ini berfungsi sebagai supply tegangan untuk ADC. Untuk pin ini harus dihubungkan secara terpisah dengan VCC karena pin ini digunakan untuk analog saja. Bahkan jika ADC pada AVR tidak digunakan tetap saja disarankan untuk menghubungkannya secara terpisah dengan VCC. Jika ADC digunakan, maka AVcc harus dihubungkan ke VCC melalui low pass filter.

- AREF

Merupakan pin referensi jika menggunakan ADC.

\section{GAMBAR RANGKAIAN}

Rangakaian sistem pengendali rob ditunjukkan pada Gambar 17.

\section{PENGUJIAN ALAT}

Pengujian ”Alat Pembaca Ketinggian Level Air Menggunakan 7segment Sebagai Pendeteksi Dini Penanggulangan Banjir Rob Berbasis PLC” ini bertujuan untuk mendapatkan data-data yang sesuai dengan yang diharapkan. Pengujian dilakukan untuk mendapatkan kesesuaian alat dengan rencana awal.

Untuk mendapatkan data yang benar dan lengkap pada saat pengujian, maka dibutuhkan kecermatan dan percobaan berulang-ulang. Hasil pengujian ditunjukkan pada tabel 1 dan tabel 2. 


\section{KESIMPULAN}

Kesimpulan yang dapat diambil dalam percobaan ini adalah :

- $\quad$ Fungsi catu daya pada alat ini adalah sebagai sumber tegangan DC yang sebelumnya adalah tegangan PLN 220 VAC diturunkan menjadi 5 VDC, 12 VDC dan 24 VDC melalui dioda bridge, IC, capasitor dan transistor.

- $\quad$ Sensor memiliki peran sebagai pendeteksi ketinggian level air yang nantinya akan mengirimkan data melalui PLC ke LCD, LED dan Buzzer serta seven segment. Setiap level sensor memiliki peran yang berbeda, yang mana akan mengirimkan data/input untuk komponen output yang berbeda pula.

- $\quad$ LED dan Buzzer bekerja pada saat sensor air selokan mencapai level maksimum sebagai peringatan meluapnya air selokan.

- $\quad$ Seven segment menampilkan karakter angka yang menunjukkan level ketinggian air sungai maupun selokan.

- $\quad$ LCD menampilkan peringatan meluapnya air selokan melalui karakter kata yang dapat dibaca secara jelas.

\section{DAFTAR PUSTAKA}

1. B. L. Teraja dan A. K. .Teraja. 1998. A Text Book Of Technology. Yogyakarta, Andi Offset

2. Eko Putra, Agfianto. 2007. PLC : Konsep,Pemrograman, dan Aplikasi. Yogyakarta: Gava Media

3. Malvino, Albert Paul. 1979. Prinsip-Prinsip Elektronika. Jakarta: Erlangga.

4. Omron. 1999. A Beginner's Guide To PLC . Yogyakarta: Gava Media

5. Petruzella, Frank D. 1996. Elektronika Industry. Yogyakarta: Andi Offset

6. Sumanto, M.A . 1995. Teori Transformator. Yogyakarta: Andi Offset

7. Surono, dkk. 2010. Bahasa Indonesia untuk Perguruan Tinggi. Semarang: Fasindo

8. Wasito . 1998. Vandemekum Elektronika. Jakarta: Elek Media Komputindo

9. Widodo, Sri Thomas . 2002. Elektronika Dasar. Jakarta: Salemba Teknika

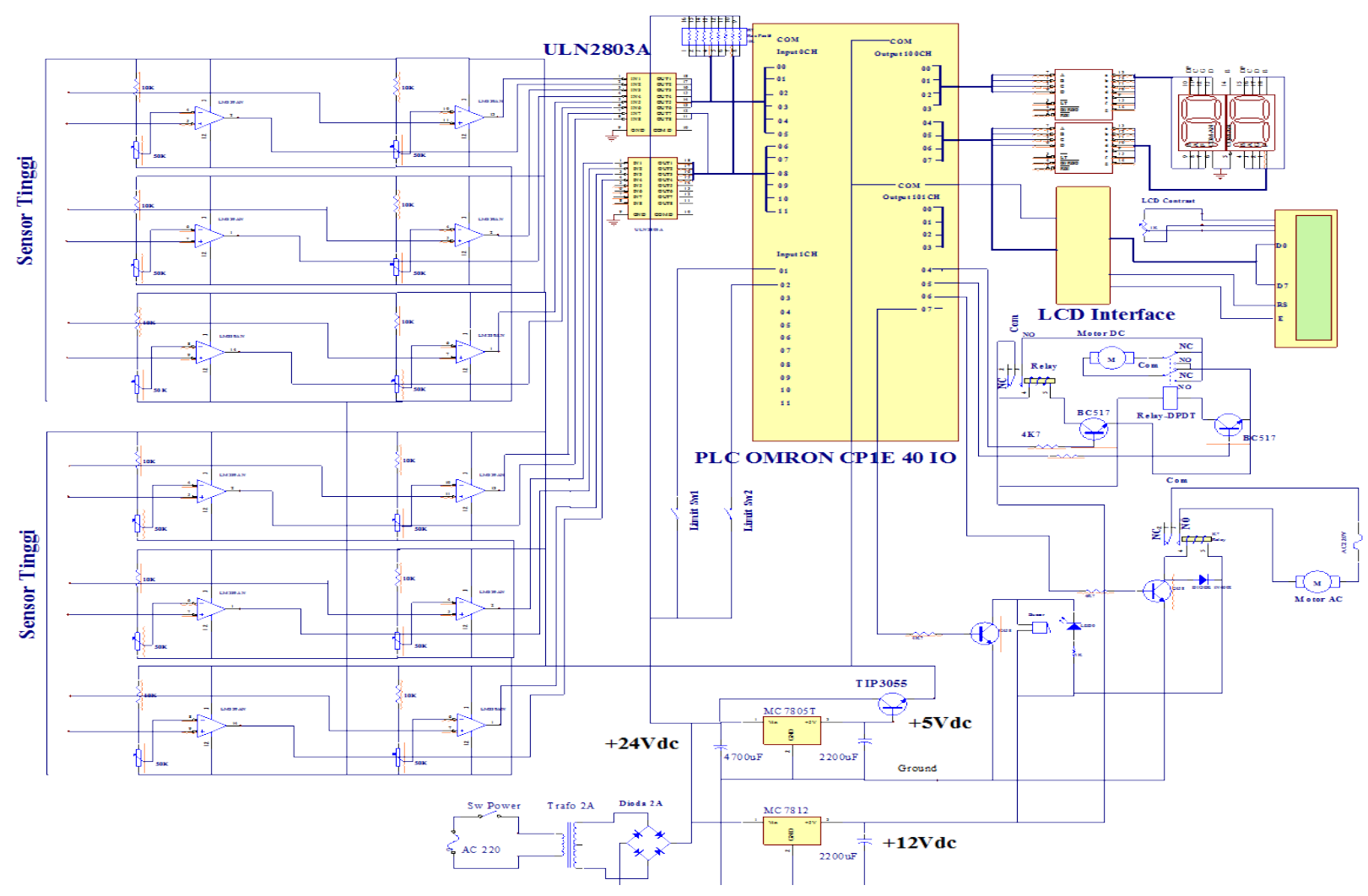

Gambar 17. Rangkaian pengendali rob 
Tabel 1. Pengujian sensor sungai

\begin{tabular}{|c|c|c|c|}
\hline Level Air & Ketinggian & Sensor & Keterangan \\
\hline 0 & $0 \mathrm{~cm}-0,4 \mathrm{~cm}$ & $\mathrm{ON}$ & $\begin{array}{l}7 \text { segment karakter } 0 \\
\text { Pintu air buka } \\
\text { Pompa off } \\
\text { Buzzer off } \\
\text { Led off } \\
\text { LCD - }\end{array}$ \\
\hline 1 & $0,5 \mathrm{~cm}-1,9 \mathrm{~cm}$ & $\mathrm{ON}$ & $\begin{array}{l}7 \text { segment karakter } 1 \\
\text { Pintu air buka } \\
\text { Pompa off } \\
\text { Buzzer off } \\
\text { Led off } \\
\text { LCD - }\end{array}$ \\
\hline 2 & $2,0 \mathrm{~cm}-3,4 \mathrm{~cm}$ & $\mathrm{ON}$ & $\begin{array}{l}7 \text { segment karakter } 2 \\
\text { Pintu air buka } \\
\text { Pompa off } \\
\text { Buzzer off } \\
\text { Led off } \\
\text { LCD - }\end{array}$ \\
\hline 3 & $3,5 \mathrm{~cm}-4,9 \mathrm{~cm}$ & $\mathrm{ON}$ & $\begin{array}{l}7 \text { segment karakter } 3 \\
\text { Pintu air buka } \\
\text { Pompa off } \\
\text { Buzzer off } \\
\text { Led off } \\
\text { LCD - }\end{array}$ \\
\hline 4 & $5,0 \mathrm{~cm}-6,4 \mathrm{~cm}$ & $\mathrm{ON}$ & $\begin{array}{l}7 \text { segment karakter } 4 \\
\text { Pintu air buka } \\
\text { Pompa off } \\
\text { Buzzer off } \\
\text { Led off } \\
\text { LCD - }\end{array}$ \\
\hline 5 & $6,5 \mathrm{~cm}-7,9 \mathrm{~cm}$ & $\mathrm{ON}$ & $\begin{array}{l}7 \text { segment karakter } 5 \\
\text { Pintu air tutup } \\
\text { Pompa off } \\
\text { Buzzer off } \\
\text { Led off } \\
\text { LCD - }\end{array}$ \\
\hline 6 & $8,0 \mathrm{~cm}$ & $\mathrm{ON}$ & $\begin{array}{l}7 \text { segment karakter } 5 \\
\text { Pintu air tutup } \\
\text { Pompa off } \\
\text { Buzzer off } \\
\text { Led off } \\
\text { LCD - }\end{array}$ \\
\hline
\end{tabular}


Tabel 2. Pengujian sensor selokan

\begin{tabular}{llll}
\hline Level Air & Ketinggian & Sensor & Keterangan \\
\hline 0 & $0 \mathrm{~cm}-4,9 \mathrm{~cm}$ & ON & 7 segment karakter 0 \\
& & Pintu air buka \\
& & Buzzer off \\
& & Led off \\
& & Pompa off \\
& & LCD karakter aman \\
\hline 1 & & 7 segment karakter 1 \\
& & Pintu air buka \\
& & Buzzer off \\
& & Led off \\
& & Pompa off \\
& & LCD karakter aman \\
\hline 2 & & 7 segment karakter 2 \\
& & Pintu air tutup \\
& & Buzzer on \\
& & Led on \\
& & Pompa off \\
& & LCD karakter waspada \\
\hline $3,5 \mathrm{~cm}-7,9 \mathrm{~cm}$ & & 7 segment karakter 3 \\
& & Pintu air tutup \\
& & Buzzer on \\
& & Led on \\
& & Pompa on \\
& & LCD karakter bahaya \\
\hline & &
\end{tabular}

